\title{
Analysis of a High-Strength Steel SMAW Database
}

\author{
A constraints-based model offers a simple framework for organizing and analyzing a \\ large SMAW database to gain valuable insights
}

\author{
BY K. SAMPATH
}

\begin{abstract}
Recently, Dr. Glyn M. Evans posted a large shielded metal arc (SMA) weld metal (WM) database on the ResearchGate website (researchgate.net). This database contains more than 950 WM compositions, along with their respective WM tensile and Charpy V-notch (CVN) impact properties. In particular, the CVN impact properties list the test temperatures that achieved 28 and $100 \mathrm{~J}$ impact energy for each WM composition. While the availability of this SMA WM database is a valuable and rare gift to the welding community, how could the welding community analyze this database to gain valuable insights? This paper utilizes a constraints-based model (CBM) as a simple and effective framework to organize and analyze this very large Fe-C-Mn SMA WM database. A CBM is built on the metallurgical principle that one needs to lower relevant solid-state phase transformation (i.e., austenite decomposition) temperatures to improve WM strength and fracture toughness while simultaneously reducing carbon content and Yurioka's carbon equivalent number (CEN) to improve the weldability of high-strength steels. To this end, a CBM identifies and simultaneously solves several statistical (regression) equations that relate the chemical composition of highstrength steel WM with Yurioka's CEN and selected solidstate phase transformation temperatures related to austenite decomposition. The results of the current effort demonstrate that the analysis of Evans's shielded metal arc welding database using a CBM as a framework reaffirms that controlling carbon content, the value of the CEN, and calculated solidstate phase transformation temperatures, particularly the difference between the calculated $B_{s}$ (bainite-start) and $M_{s}$ (martensite-start) temperatures, is critical to developing and identifying high-performance, high-strength steel welding electrodes. A dual approach that manipulates the contents of principal alloy elements such as $\mathrm{C}, \mathrm{Mn}, \mathrm{Ni}, \mathrm{Cr}, \mathrm{Mo}$, and $\mathrm{Cu}$, and adds controlled amounts of Ti, B, Al, $\mathrm{O}$, and $\mathrm{N}$, appears to offer the best means to lower relevant solid-state phase transformation temperatures to produce high-strength and hightoughness WMs.
\end{abstract}

\section{KEYWORDS}

- Electrode Development • Constraints-Based Modeling

- Transformation Temperature - Database

- Shielded Metal Arc Welding

\section{Introduction}

Recently, Dr. Glyn M. Evans (formerly with Oerlikon, Switzerland) posted a large shielded metal arc (SMA) weld metal (WM) database on the ResearchGate website (Ref. 1). This database contains more than 950 WM compositions along with their respective WM tensile and Charpy V-notch (CVN) impact properties. These WM compositions belong to 74 types of $\mathrm{Fe}-\mathrm{C}-\mathrm{Mn}$ alloy systems and were derived from the book Metallurgy of Basic Weld Metal, by G. M. Evans and N. Bailey (Ref. 2). Spreadsheet \#1 of the Microsoft ${ }^{\circledR}$ Excel $^{\circledR}$ workbook, Analysis of G. M. Evans Shielded Metal Arc Welding (SMAW) Database, available on the American Welding Society (AWS) website at aws.org/2021.100.036-database, shows the Fe-C-Mn alloy systems involving 74 types of alloy systems. Of these 74 types of Fe-C-Mn alloy systems, Table 1 shows the top 20 types that offered the highest number of WM compositions. Together, these 20 types accounted for 645 WM compositions.

These experimental SMAW electrodes belonged to the basic type. The test weld deposits were produced using standardized procedures at Oerlikon Welding Ltd., Zurich, Switzerland, according to International Organization for Standardization (ISO) 2560, Welding consumables - Covered electrodes for manual metal arc welding of non-alloy and fine grain steels - Classification, at a nominal $1 \mathrm{~kJ} / \mathrm{mm}$ (about 25 $\mathrm{kJ} / \mathrm{in}$.) heat input, $200^{\circ} \mathrm{C}$ interpass temperature, and $20-\mathrm{mm}$ plate thickness by a single master welder. Figure 1 shows a typical macrograph of a test weld, the CVN being centrally located as shown by the vertical red line, as specified in ISO 2560

The individual chemical compositions of the WMs in the SMAW database varied over a wide range. For example, the $C$ content varied between 0.035 and 0.152 wt- $\%$, Mn content between 0.23 and 2.1 wt-\%, $\mathrm{Cr}$ content between 0.026 and 3.5 wt- $\%$, Ni content between 0.03 and 5.48 wt-\%, Mo content between 0.005 and $1.16 \mathrm{wt}-\%, \mathrm{Cu}$ content between 0.02 and 2.04 wt-\%, Ti content between 0.0001 and 0.077 wt-\%, and B content between 0.0001 and 0.02 wt- $\%$ with nominal levels of other elements such as $\mathrm{Al}, \mathrm{V}, \mathrm{Nb}(\mathrm{Cb}), \mathrm{N}$, and O. Table 2 shows the low, high, and range of individual elements in the chemical composition of the WMs in the SMAW database. This large SMAW database is a valuable 
Table 1 - Top 20 Types of Fe-C-Mn Alloy Systems of 963 Weld Metal (WM) Database

\begin{tabular}{ccc} 
No. & Type of Fe-C-Mn Alloy System & No. of WM Compositions \\
\hline 1 & TiBN & 101 \\
2 & Tab & 96 \\
3 & CB & 44 \\
4 & TiB & 39 \\
5 & AlTi & 33 \\
6 & AlO & 27 \\
7 & CrMo & 26 \\
8 & ACuTi & 25 \\
9 & ANiTi & 25 \\
10 & TiN & 24 \\
11 & TiOX & 24 \\
12 & AlN & 21 \\
13 & A5Ni & 20 \\
14 & AMoTi & 20 \\
15 & MnCr & 20 \\
16 & MnNb & 20 \\
17 & MnNi & 20 \\
18 & MnTi & 20 \\
19 & MnV & 20 \\
20 & ACrTi & 20 \\
& Total & 645 \\
\hline
\end{tabular}

and rare gift to the welding community because it provides ready access to a wealth of data.

Additionally, the Evans database lists the test temperatures that achieved 28 and $100 \mathrm{~J}$ CVN impact energy for each WM composition (Spreadsheet \#1, Evans SMAW Database). Based on additional extensive testing of CVN impact properties over a broad range of test temperatures, Evans further identified four WM compositions as the best in class among the Fe-C-Mn WM compositions in the SMAW database. These four best-in-class WMs belonged to different types of Fe-C-Mn alloy types, namely rows \#139 (AlO), \#369 (CB), \#741 (TiBAlN), and \#936 (TiOX) in Spreadsheet \#1. Spreadsheet \#2, "Best-in-Class," separately lists these WMs. Figure 2 shows the variation of WM CVN impact toughness with the test temperatures of the four best-in-class WMs, with transition in impact toughness occurring at about 145 $\mathrm{J}$ and $-70^{\circ} \mathrm{C}$. Table 3 lists the corresponding WM chemical compositions while Table 4 lists the WM tensile and CVN impact properties with test temperatures that achieved 28 and $100 \mathrm{~J}$ impact energy.

While the availability of a very large SMA WM database involving a wide variety of $\mathrm{Fe}-\mathrm{C}-\mathrm{Mn} \mathrm{WM}$ compositions with the corresponding WM tensile and CVN impact test results is a valuable resource for the welding community, a reader might wonder how the welding community could analyze this database to gain valuable insights? For example, why would four different types of Fe-C-Mn alloy systems, namely

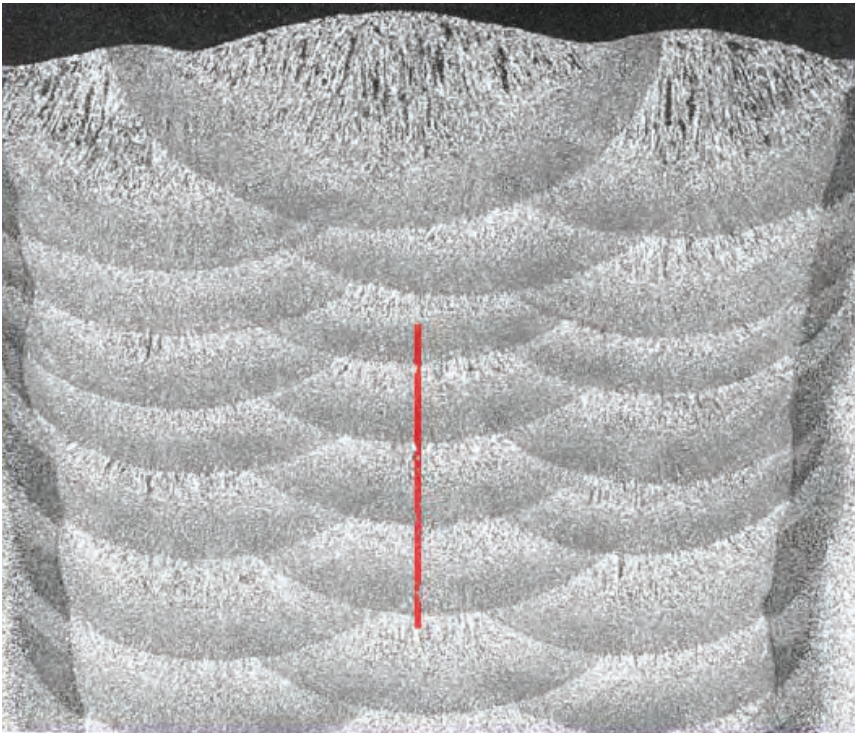

Fig. 1-Cross section of a typical test weldment with three beads per layer (Ref. 3).

AlO, CB, TiBAlN, and TiOX, provide WMs with nearly identical impact toughness behavior over a broad range of test temperatures? This paper offers the previously published (Refs. 4-6) constraints-based model (CBM) as an appropriate and effective framework for organizing and analyzing this database to gain valuable insights.

\section{Constraints-Based Model}

Commonly, new welding electrode development efforts involve the use of trial-and-error methods to identify a good candidate alloy system. Subsequent efforts further develop/ evaluate the candidate alloy into a successful electrode. This traditional approach is often risky and takes enormous time and effort to analyze the results carefully and progressively, while also requiring extensive funding.

In contrast, the early 1990s witnessed the successful development of a set of ER100S and ER120S highperformance solid wire electrodes for gas metal arc welding (GMAW) of high-strength steels such as HY-100, HY-80, HSLA-100, HSLA-80, etc. used in U.S. Navy aircraft and submarine construction (Ref. 4). This successful effort used an innovative approach that employed two specific aspects. First, it consolidated existing metallurgical knowledge on chemical-composition-processing-microstructure development and mechanical properties of high-strength steels. Second, it reached beyond existing knowledge on electrode development and, in particular, avoided the selection of rich

Table 2 - Low, High, and Range of Individual Elements in the Chemical Composition of 963 Weld Metals (wt-\%)

\begin{tabular}{cccccccccccccccccc} 
& $\mathrm{C}$ & $\mathrm{Mn}$ & $\mathrm{P}$ & $\mathrm{S}$ & $\mathrm{Si}$ & $\mathrm{Cr}$ & $\mathrm{Ni}$ & $\mathrm{Mo}$ & $\mathrm{V}$ & $\mathrm{Nb}$ & $\mathrm{Cu}$ & $\mathrm{Ti}$ & $\mathrm{N}$ & 0 & $\mathrm{Al}$ & $\mathrm{B}$ \\
\hline Low & 0.035 & 0.23 & 0.003 & 0.003 & 0.001 & 0.026 & 0.03 & 0.005 & 0.0003 & 0.0003 & 0.02 & 0.0001 & 0.0035 & 0.022 & 0.0001 & 0.0001 \\
High & 0.152 & 2.1 & 0.04 & 0.046 & 1.11 & 3.5 & 5.48 & 1.16 & 0.2873 & 0.098 & 2.04 & 0.077 & 0.027 & 0.154 & 0.068 & 0.02 \\
Range & 0.117 & 1.87 & 0.037 & 0.043 & 1.109 & 3.474 & 5.45 & 1.155 & 0.287 & 0.0977 & 2.02 & 0.0769 & 0.0235 & 0.132 & 0.068 & 0.0199 \\
\hline
\end{tabular}




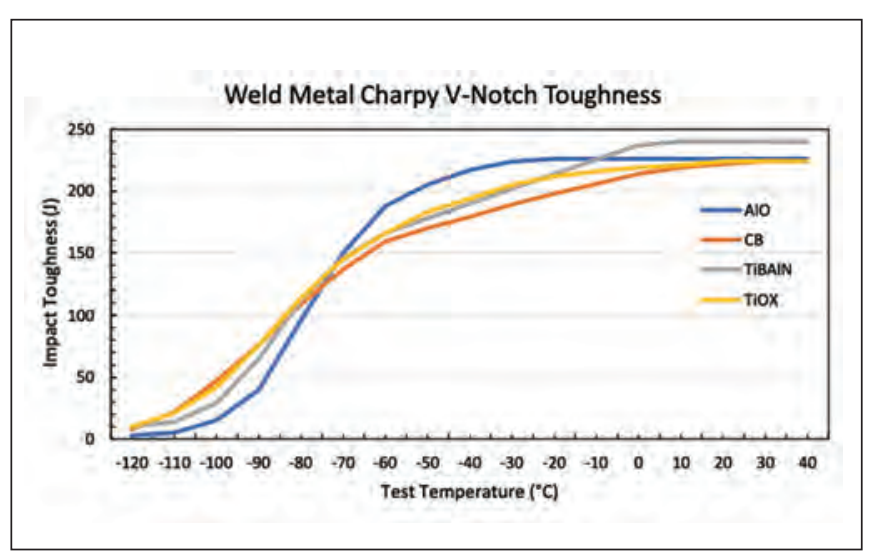

Fig. 2 - Variation of CVN impact toughness with test temperatures of the four best-in-class WMs.

and lean compositions within the required electrode specification range. A rich composition refers to most principal elements such as $\mathrm{C}, \mathrm{Mn}, \mathrm{Ni}, \mathrm{Cr}, \mathrm{Mo}$, and $\mathrm{Cu}$ at or near the top of the specification range, while a lean composition refers to most of the above principal elements at or near the bottom of the specification range. These two aspects allowed the newly developed $1 / 16$-in.-diameter (1.6-mm-diameter) ER100S and ER120S GMAW wire electrodes to meet the U.S. Navy requirements for high WM strength, exceptional fracture toughness, and a wider welding operational envelope while reducing risk, time, and effort. The wider welding operational envelope involved qualifying the newly developed electrodes based on one-side welding of 1-in.-thick (25.4$\mathrm{mm}$-thick) plates with a single-V-groove preparation and a $1 / 2$-in. (12-mm) root opening using 95\% Ar-5\% CO 2 shielded gas mix with welding heat input ranging from 35 to 110 $\mathrm{kJ} / \mathrm{in}$. (about 1.4 to $4.3 \mathrm{~kJ} / \mathrm{mm}$ ) per pass, multipass welding with controlled preheat, interpass, post-soak temperature regimes, etc.

This pioneering effort involved the development and use of a CBM (Ref. 4). The constraints refer to the selection of numerical ranges for Yurioka's carbon equivalent number (CEN) and solid-state phase transformation temperatures related to the decomposition of austenite, such as $\mathrm{A}_{\mathrm{r} 3}$ (austenite to ferrite), $B_{s}$ (bainite-start), $B_{f}$ (bainite-finish), $M_{s}$ (martensitestart) temperatures, etc. These specific metallurgical characteristics are related to the chemical composition of highstrength steels through statistical (regression) equations. The CBM identifies and simultaneously solves the above set of regression equations in a mutually inclusive fashion to meet certain numerical ranges for the chemical composition and specific metallurgical characteristics of interest. The constraints and their numerical ranges themselves underscore the metallurgical principle that depending on the desired WM microstructure, one needs to lower relevant solid-state phase transformation temperatures to improve WM strength and fracture toughness while simultaneously reducing the carbon content and CEN to improve weldability. The desired WM microstructure could be either predominantly diffusional transformation products (such as acicular ferrite) when the desired WM strength is $700 \mathrm{MPa}$ (100 ksi) or below or predominantly athermal transformation products (such as bainite and/or martensite) when the desired WM strength is far in excess of

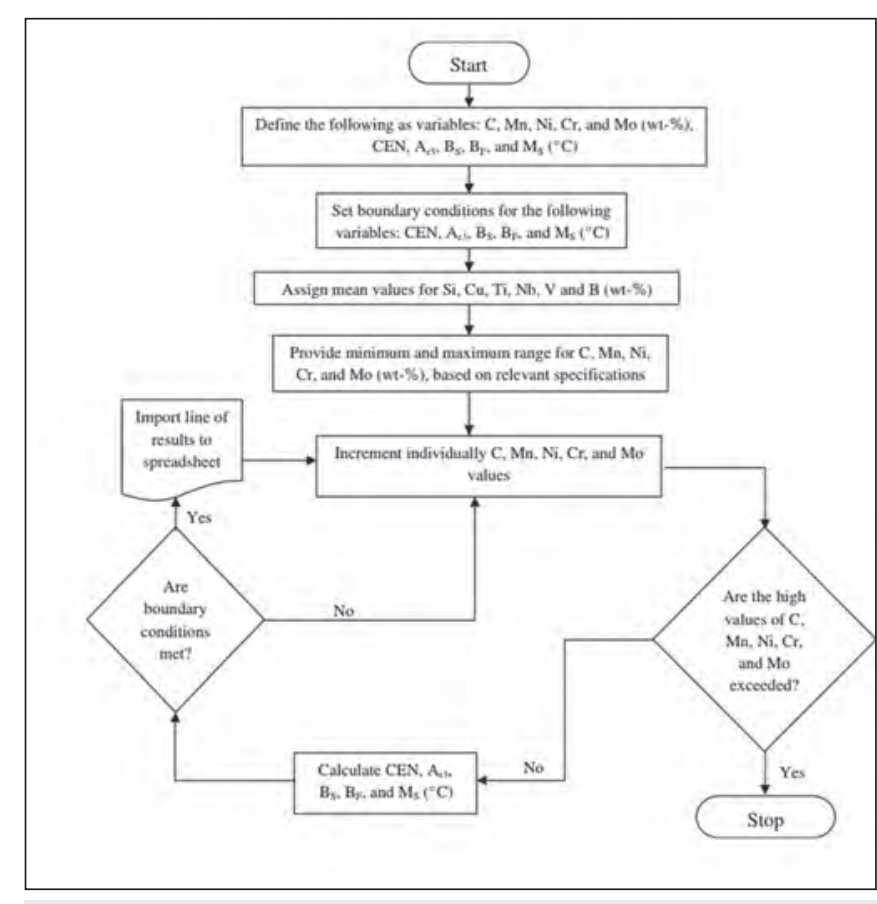

Fig. 3 - A typical flowchart used with computer programming associated with a CBM (Ref. 6).

$700 \mathrm{MPa}(100 \mathrm{ksi})$. In this continuum, one must realize that indiscriminate lowering of solid-state phase transformation temperatures could result in violation of the common progression of transformation temperatures, wherein $A_{r 3}>B_{s}>B_{f}>$ $\mathrm{M}_{\mathrm{s}}$, and lead to adverse consequences, particularly on WM toughness when diffusional transformation products are desired in the WM microstructure. When athermal transformation products are desired in the WM microstructure, one could consider suitably manipulating the differences among the calculated values of $B_{s}, B_{50}$, or $B_{f}$ and $M_{s}$ temperatures (Ref. 4).

Inter alia, the mutually inclusive conditions placed on the numerical ranges for various statistical equations lead to specific constraints on the choice of the principal alloy elements like $\mathrm{C}, \mathrm{Mn}, \mathrm{Ni}, \mathrm{Cr}, \mathrm{Mo}$, and $\mathrm{Cu}$ together with specific boundary conditions for calculated metallurgical characteristics such as the $C E N, B_{s}, B_{f}, M_{s}$, etc. The corresponding numerical values for the calculated metallurgical characteristics were based on similarly calculated characteristics of relevant base metals. In other words, the CBM employs a mathematical approach to address specific metallurgical needs in which the outcome of each decision is constrained by minimum and maximum limits as detailed in the boundary conditions for various elements and the calculated metallurgical characteristics. Decision variables such as the $C E N, B_{s}, B_{f}$, $M_{s}$, etc. that share a common constraint such as a specified chemical composition range for principal alloy elements must also have their solution values fall within the bounds of the various constraints.

The various calculations associated with this metallurgical and mathematical modeling can be performed using either a scientific calculator, a commercially available Microsoft Excel or similar software, or a suitably designed computer software program. Figure 3 shows a typical flowchart used to identify electrode or WM compositions with 
Table 3-Chemical Composition of the Four Best-in-Class Weld Metals

\begin{tabular}{|c|c|c|c|c|c|c|c|c|c|c|c|c|c|c|c|c|}
\hline \multirow{2}{*}{$\begin{array}{l}\text { Row \#*, } \\
\text { Heat ID }\end{array}$} & \multicolumn{16}{|c|}{ Weld Metal Chemical Composition (wt-\%) } \\
\hline & C & $\mathrm{Mn}$ & $P$ & S & $\mathrm{Si}$ & $\mathrm{Cr}$ & $\mathrm{Ni}$ & Mo & V & $\mathrm{Nb}$ & $\mathrm{Cu}$ & $\mathrm{Ti}$ & $\mathrm{N}$ & 0 & Al & B \\
\hline 139, AlO & 0.083 & 1.35 & 0.011 & 0.004 & 0.47 & 0.03 & 0.03 & 0.005 & 0.0005 & 0.0005 & 0.03 & 0.003 & 0.0049 & 0.03 & 0.012 & 0.0002 \\
\hline $369, \mathrm{CB}$ & 0.075 & 1.50 & 0.01 & 0.006 & 0.40 & 0.03 & 0.03 & 0.005 & 0.0005 & 0.0005 & 0.03 & 0.039 & 0.0085 & 0.0297 & 0.0005 & 0.0051 \\
\hline 741, TiBAIN & 0.07 & 1.56 & 0.01 & 0.007 & 0.49 & 0.03 & 0.03 & 0.005 & 0.0005 & 0.0005 & 0.03 & 0.042 & 0.0067 & 0.0438 & 0.016 & 0.0048 \\
\hline 936, TiOX & 0.085 & 1.63 & 0.01 & 0.004 & 0.34 & 0.03 & 0.03 & 0.005 & 0.0005 & 0.0005 & 0.03 & 0.0025 & 0.0068 & 0.0276 & 0.0005 & 0.0002 \\
\hline
\end{tabular}

*Row \# refers to Spreadsheet \#1 of MS Excel Workbook, Analysis of G. M. Evans SMAW Database.

\begin{tabular}{|c|c|c|c|c|c|c|}
\hline \multirow{2}{*}{$\begin{array}{l}\text { Row \#, } \\
\text { Heat ID }\end{array}$} & \multirow[b]{2}{*}{$\begin{array}{c}\mathrm{YS} \\
\left(\mathrm{N} / \mathrm{mm}^{2)}\right.\end{array}$} & \multicolumn{2}{|c|}{ Weld Metal Tensile Properties } & \multirow[b]{2}{*}{$\begin{array}{l}\text { RA } \\
(\%)\end{array}$} & \multicolumn{2}{|c|}{ CVN Test Temperature $\left({ }^{\circ} \mathrm{C}\right)$} \\
\hline & & $\begin{array}{c}\text { UTS } \\
\left(\mathrm{N} / \mathrm{mm}^{2}\right)\end{array}$ & $\begin{array}{c}\mathrm{El} \\
(\%)\end{array}$ & & @ 100 J & @ 28 J \\
\hline 139, AlO & 492 & 558 & 26.4 & 81.6 & -80 & -94 \\
\hline $369, \mathrm{CB}$ & 514 & 571 & 28 & 79 & -83 & -108 \\
\hline 741, TiBAIN & 610 & 640 & 27.2 & 73.4 & -83 & -100 \\
\hline 936, TiOX & 489 & 560 & 26.8 & 80.7 & -84 & -106 \\
\hline
\end{tabular}

*Row \# refers to Spreadsheet \#1 of MS Excel Workbook, Analysis of G. M. Evans SMAW Database.

the desired minimum and maximum range of limits as detailed in the boundary conditions for various elements within an electrode specification and the boundary conditions for the desired calculated metallurgical characteristics of the WM (Ref. 6).

While the chemical composition ranges of actual electrodes and WMs include other elements such as $\mathrm{S}, \mathrm{P}, \mathrm{Si}, \mathrm{Nb}$ (Cb), V, Ti, Al, Zr, etc., the control of these other elements and the total gas (hydrogen, oxygen, and nitrogen) content is critical to eliminate weld defects and to promote desirable combinations in WM microstructure development. Depending on their nominal content and actual effects during welding and/or following post-soak heat treatment, these other elements either enhance or impair WM soundness, cleanliness, and mechanical properties, particularly lowtemperature impact toughness.

The development of a CBM in successfully addressing U.S. Navy needs for high-performance ER100S and ER120S electrodes along with details of the model, underlying metallurgical rationale, and subsequent validation of the model are described in Ref. 4. Most importantly, use of the above mutually inclusive constraints allowed the elimination of the traditional trial-and-error method used in electrode development and, in particular, avoided the selection of rich and lean compositions within the required electrode specification range. Instead, the constraints enabled the production of a set of eight electrodes, based on a $2^{3}$ Taguchi design, all in one go. The $2^{3}$ Taguchi design varied the contents of only three principal alloy elements, namely $\mathrm{Mn}, \mathrm{Ni}$, and Mo, each at two levels, one high and the other low, while keeping all other elements at a fairly constant level (Ref. 4). Vacuum induction melting (VIM) was used to produce the billets for electrode manufacturing. The use of VIM limited the total gas content far below $500 \mathrm{ppm}$. This innovative approach yielded two of eight electrodes that met or exceeded the ER100S requirements and one of eight electrodes that met or exceeded the ER120S requirements, thus affirming the merit and utility of the CBM. The related research on the actual chemical compositions of the eight experimental electrodes was published (Ref. 4) following the award of U.S. Patent 5,744,782 in 1998 (Ref. 7). The WMs showed a predominantly bainitic microstructure (Ref. 8) that was also insensitive to hydrogen-assisted cracking. Thus, the CBM approach to successfully developing high-performance, high-strength steel welding electrodes for joining HY-100, HY-80, HSLA-100, and HSLA-80 steels substantially eliminated risk and reduced cost while meeting stringent schedule requirements.

In subsequent years, the CBM was used in combination with a $\mathrm{C}++$ algorithm (Ref. 5) to comparatively evaluate two competing U.S. Patents - 5,523,540 (Ref. 9) and 5,744,782 (Ref.7) — against AWS A5.28, Specification for Low-Alloy Steel Electrodes and Rods for Gas Shielded Arc Welding, (or MIL-E-23765/2, Electrodes and Rods - Welding, Bare, Solid, or Alloy Cored; and Fluxes, Low Alloy Steel) for the chemical composition range of the electrodes and the mechanical properties of the WMs. Table 5 shows the MIL-E-23765/2 specification requirements and the ranges of the chemical compositions of the specific elements claimed in the two U.S.

Patents. Interestingly, such a comparative evaluation is possible only with the aid of the CBM.

The $\mathrm{C}++$ algorithm specified desirable numerical ranges for each of the principal elements as detailed in the U.S. Patent 5,523,540 (Ref. 9), U.S. Patent 5,744,782 (Ref. 7), or MIL-E-23765/2 (or AWS A5.28) electrode specification and the boundary conditions for the CEN, $\mathrm{B}_{s}, \mathrm{~B}_{\mathrm{f}}, \mathrm{M}_{\mathrm{s}}$, etc. that would enable the development of high-performance WM microstructures with predominantly athermal transformation products. The results of this comparative evaluation showed the U.S. Patent 5,744,782 (Ref. 7) offered more possibilities to design and produce high-strength steel welding electrodes to provide high-performance WMs. The above com- 


\begin{tabular}{|c|c|c|c|c|c|c|c|c|}
\hline \multirow{2}{*}{$\begin{array}{c}\text { Element } \\
\text { (wt-\%) }\end{array}$} & \multicolumn{2}{|c|}{ MIL-E-23765/2E Range } & \multicolumn{3}{|c|}{ U.S. Patent 5,523,540 (Ref. 9) } & \multicolumn{3}{|c|}{ U.S. Patent 5,744,782 (Ref. 7) } \\
\hline & MIL-100S & MIL-120S & Minimum & Maximum & Range Claimed & Minimum & Maximum & Range Claimed \\
\hline Carbon & $<0.08$ & $<0.1$ & 0.012 & 0.035 & $0.01-0.05$ & 0.026 & 0.030 & $<0.06$ \\
\hline Manganese & $1.25-1.80$ & $1.4-1.80$ & 0.89 & 1.69 & $0.70-1.80$ & 1.49 & 1.82 & $1-2$ \\
\hline Phosphorus & & & 0.008 & 0.012 & & 0.001 & 0.001 & $<0.01$ \\
\hline Sulfur & & & 0.003 & 0.012 & & 0.018 & 0.023 & $<0.01$ \\
\hline Silicon & $0.20-0.55$ & $0.25-0.60$ & 0.27 & 0.36 & $0.20-0.40$ & 0.33 & 0.37 & $0.2-0.5$ \\
\hline Chromium & $<0.3$ & $<0.6$ & 0.01 & 0.6 & $<0.80$ & 0.01 & 0.02 & \\
\hline Nickel & $1.40-2.10$ & $2.0-2.80$ & 2.46 & 5.92 & $2.0-9.0$ & 2.38 & 3.78 & $2-4$ \\
\hline Molybdenum & $0.25-0.55$ & 0.30-1.10 & 0.44 & 0.96 & $0.40-1.50$ & 0.51 & 0.99 & ו-0.3 \\
\hline Vanadium & & & 0.004 & 0.01 & $<0.01$ & 0.001 & 0.003 & \\
\hline Niobium & & & 0 & 0 & & 0 & 0 & \\
\hline Copper & $<0.25$ & $<0.25$ & 0 & 0 & $<1.0$ & 0.001 & 0.20 & $<0.5$ \\
\hline Titanium & $<0.1$ & $<0.1$ & 0.003 & 0.045 & $<0.03$ & 0.025 & 0.0033 & $<0.05$ \\
\hline Aluminum & $<0.1$ & $<0.1$ & 0.001 & 0.038 & $<0.035$ & & & \\
\hline Boron & & & & & & 0.003 & 0.0057 & $<0.01$ \\
\hline Oxygen (ppm) & & & & & & 47 & 82 & 300 \\
\hline Nitrogen (ppm) & & & & & & 4 & 10 & 50 \\
\hline Hydrogen & & & & & & & & \\
\hline$(\mathrm{mL} / 100 \mathrm{~g})$ & & & & & & 1.15 & 2.35 & 5 \\
\hline
\end{tabular}

parative evaluation using the CBM was carried out for the very first time.

An additional research effort using the $\mathrm{CBM}$ and a $\mathrm{C}++$ algorithm allowed the metallurgical design of highperformance GMAW electrodes for joining commercial HSLA-65 steels as shown in Table 6 (Ref. 6). Here, the C++ algorithm was used to metallurgically design high-performance GMAW electrodes based on the following: (1) a carbon content

$\leq 0.06$ wt-\% for improved weldability, (2) a $5-15 \%$ lower $\mathrm{A}_{\mathrm{r} 3}$ (i.e., austenite to ferrite) transformation temperature than HSLA-65 steels for enhanced strength and toughness, and (3) a desirable range of the CEN for consistently overmatching the minimum specified tensile strength of commercial HSLA- 65 steels. The $\mathrm{C}++$ algorithm utilized a set of boundary conditions that included calculated $\mathrm{A}_{\mathrm{r}}, \mathrm{B}_{\mathrm{s}}, \mathrm{B}_{\mathrm{f}}$, and $\mathrm{M}_{\mathrm{s}}$ transformation temperatures besides the $C E N$. The calculated transformation temperatures were also set to meet the condition that $A_{r 3}>B_{s}>B_{f}>M_{s}$. The combination of the $\mathrm{CBM}$ with $\mathrm{C}++$ offers the only means to integrate the chemical composition ranges mentioned in a specification or patented claims and use the regression equations to meet numerical ranges for appropriate boundary conditions, thereby leading to specific outcomes.

Numerical ranges for the various boundary conditions were derived from an analysis of the chemical compositions of commercial HSLA-65 steels (Refs. 6,10 ). The boundary conditions were applied in evaluating chemical composition ranges of the following three prospective welding electrode specification groups belonging to AWS A5.28 that offered to provide $\leq 0.06 \mathrm{wt}-\%$ carbon, a minimum transverse-weld tensile strength of $552 \mathrm{MPa}(80 \mathrm{ksi})$, and a minimum CVN impact toughness of $27 \mathrm{~J}$ at $-29^{\circ} \mathrm{C}$ through $-51^{\circ} \mathrm{C}$ in the aswelded condition: (1) ER80S-Ni1, (2) E90C-K3, and (3) E80C-W2. At $\leq 0.06$ wt-\% carbon, the $C++$ algorithm returned more than 3100 results for E90C-K3 that satisfied the boundary conditions but returned no acceptable results for the other two electrode specification groups. Results revealed that welding electrode designs featuring an $\mathrm{Fe}-\mathrm{C}-\mathrm{Mn}$ -
Ni-Mo system containing 0.06 wt-\% C, 1.6 wt-\% Mn, 0.8 wt$\% \mathrm{Ni}$, and $0.3 \mathrm{wt}-\% \mathrm{Mo}$ and providing WMs characterized by an $\mathrm{A}_{\mathrm{r} 3}$ of $690^{\circ} \mathrm{C}$, a CEN of 0.29 , and a $\left(\mathrm{B}_{\mathrm{f}}-\mathrm{M}_{\mathrm{s}}\right)$ of $30^{\circ} \mathrm{C}$ are expected to consistently overmatch the minimum specified tensile strength of HSLA- 65 steel while offering a minimum CVN impact toughness of $41 \mathrm{~J}$ at $-40^{\circ} \mathrm{C}$.

A recent research effort (Ref. 11) at the Welding and Joining Institute at RWTH Aachen University, Germany, had obtained longitudinal weld tensile test results of weldments produced using the GMAW process with certain quenched and tempered (Q\&T) and thermo-mechanical control processed (TMCP) high-strength structural steels with yield strengths ranging between 690 and $1100 \mathrm{MPa}$ (or $\mathrm{N} / \mathrm{mm}^{2}$ ). This study determined a correlation existed between the longitudinal weld tensile test results and experimentally determined transformation start temperatures of the WM for the welded joints under investigation.

The above set of prior research efforts clearly demonstrates that the austenite decomposition (transformation) temperature can be used as an effective tool for metallurgically designing high-performance, high-strength welding electrodes and the microstructure of the resultant WM. The intrinsic effect of carbon on the weldability of steels is well known. Similarly, the trends on the interactive effects of other elements on weldability, strength, and fracture toughness are also well known. However, these trends are difficult to quantify in terms of desired or acceptable ranges for WM strength and CVN impact toughness, particularly when applied to a variety of Fe-C-Mn alloy systems and over a broad range of weld heat input or weld cooling rates. Interestingly, the CBM approach allows one to capture these known trends in terms of certain calculated metallurgical characteristics and box them in selected numerical ranges, thereby allowing one to obtain desirable WM microstructures predominantly containing either diffusional or athermal transformation products and resultant mechanical properties that exceed minimum specified requirements. The boxing also enables one to achieve an adequate buffer for the effects of the weld heat input and the associated range of the weld 
Table 6-ASTM A945 Specification Requirements and Typical Chemical Compositions of Commercial HSLA-65 and Title III Plate Steels (Refs. 6, 10)

\begin{tabular}{|c|c|c|c|c|c|c|c|c|c|c|c|c|c|c|}
\hline & C & $\mathrm{Mn}$ & $P$ & s & $\mathrm{Si}$ & $\mathrm{Cr}$ & $\mathrm{Ni}$ & Mo & v & $\mathrm{Nb}$ & $\mathrm{Cu}$ & Al & Others & CEN \\
\hline ASTM A945 requirements & 0.10 & $1.10-1.65$ & 0.025 & 0.010 & $0.10-0.50$ & 0.20 & 0.40 & 0.08 & 0.10 & 0.05 & 0.35 & 0.08 & - & - \\
\hline Arcelor Mittal Steel HSLA-65 & 0.08 & 1.39 & 0.006 & 0.003 & 0.22 & 0.16 & 0.35 & 0.06 & 0.057 & 0.035 & 0.25 & 0.003 & $0.003 \mathrm{Ti}$ & 0.277 \\
\hline U.S. Steel HSLA-65 & 0.08 & 1.35 & 0.008 & 0.003 & 0.26 & 0.03 & 0.35 & 0.06 & 0.023 & 0.021 & 0.35 & - & $0.012 \mathrm{Ti}$ & 0.257 \\
\hline U.S. Steel Title III Grade 65 & 0.07 & 1.55 & 0.017 & 0.002 & 0.27 & 0.06 & 0.03 & 0.06 & - & 0.030 & 0.03 & - & - & 0.240 \\
\hline
\end{tabular}

*Single values are maximum.

Table 7-Selected Calculated Metallurgical Characteristics of the Four Best-in-Class Weld Metals

\begin{tabular}{|c|c|c|c|c|c|c|c|c|c|c|c|c|}
\hline \multirow[b]{2}{*}{$\begin{array}{l}\text { Row \#*, } \\
\text { Heat ID }\end{array}$} & \multirow[b]{2}{*}{$\mathrm{P}_{\mathrm{cm}}$} & \multirow[b]{2}{*}{$\mathrm{CE}_{\| \mathrm{IW}}$} & \multirow[b]{2}{*}{ CEN } & \multirow[b]{2}{*}{$\begin{array}{l}\mathrm{A}_{\mathrm{r} 3} \\
\left({ }^{\circ} \mathrm{C}\right)\end{array}$} & \multirow[b]{2}{*}{$\begin{array}{l}\mathrm{B}_{\mathrm{s}} \\
\left({ }^{\circ} \mathrm{C}\right)\end{array}$} & \multirow[b]{2}{*}{$\begin{array}{l}\mathrm{B}_{50} \\
\left({ }^{\circ} \mathrm{C}\right)\end{array}$} & \multicolumn{5}{|c|}{ Selected Calculated Metallurgical Characteristics } & \multirow[b]{2}{*}{$\begin{array}{c}\left(\mathrm{A}_{\mathrm{r} 3}-\mathrm{B}_{\mathrm{f}}\right) \\
\left({ }^{\circ} \mathrm{C}\right)\end{array}$} \\
\hline & & & & & & & $\begin{array}{c}\mathrm{B}_{\mathrm{f}} \\
\left({ }^{\circ} \mathrm{C}\right)\end{array}$ & $\begin{array}{l}\mathrm{M}_{\mathrm{s}} \\
\left({ }^{\circ} \mathrm{C}\right)\end{array}$ & $\begin{array}{c}\left(\mathrm{B}_{\mathrm{f}}-\mathrm{M}_{\mathrm{s}}\right) \\
\left({ }^{\circ} \mathrm{C}\right)\end{array}$ & $\begin{array}{c}\left(A_{r 3}-B_{s}\right) \\
\left({ }^{\circ} \mathrm{C}\right)\end{array}$ & $\begin{array}{c}\left(A_{r 3}-B_{50}\right) \\
\left({ }^{\circ} \mathrm{C}\right)\end{array}$ & \\
\hline 139, AlO & 0.171 & 0.397 & 0.235 & 773 & 682 & 622 & 562 & 476 & 86 & 91 & 151 & 211 \\
\hline 369, СВ & 0.193 & 0.403 & 0.248 & 764 & 671 & 611 & 551 & 475 & 76 & 93 & 153 & 213 \\
\hline 741, TiBAIN & 0.192 & 0.423 & 0.246 & 760 & 667 & 607 & 547 & 475 & 72 & 93 & 153 & 213 \\
\hline 936, TiOX & 0.181 & 0.424 & 0.263 & 750 & 657 & 597 & 537 & 466 & 71 & 93 & 153 & 213 \\
\hline
\end{tabular}

*Row \# refers to Spreadsheet \#1 of MS Excel Workbook, Analysis of G. M. Evans SMAW Database.

cooling rate on the desirable range for weld mechanical properties.

\section{Objective}

The purpose of the current effort was the following:

1) Offer the CBM as a simple and effective framework to organize and analyze the very large Fe-C-Mn SMA WM database;

2) Demonstrate how to perform an analysis of the database using the CBM; and

3) Use the results of the analysis to reaffirm that control of the $C$ content, the CEN, and calculated solid-state phase transformation temperatures provides a strong metallurgical basis for developing and evaluating high-performance, high-strength steel welding electrodes.

\section{Procedure}

The current effort used the Evans SMA Fe-C-Mn WM chemical composition database and calculated the following metallurgical characteristics using previously published constitutive (statistical or regression) equations.

$\mathrm{P}_{\mathrm{cm}}=\mathrm{C}+\mathrm{Si} / 30+(\mathrm{Mn}+\mathrm{Cu}+\mathrm{Cr}) / 20+\mathrm{Ni} / 60+\mathrm{Mo} / 15+\mathrm{V} / 10$ $+5 \times B$

$\mathrm{CE}_{\mathrm{IIW}}=\mathrm{C}+(\mathrm{Mn}+\mathrm{Si}) / 6+(\mathrm{Cr}+\mathrm{Mo}+\mathrm{V}) / 5+(\mathrm{Ni}+\mathrm{Cu}) / 15$

$\mathrm{CEN}=\mathrm{C}+\{\mathrm{A}(\mathrm{C}) \times \mathrm{EMU}\}$ where $\mathrm{A}(\mathrm{C})$ refers to the accommodation factor that is a function of the $C$ content, while EMU refers to a set of elemental multiplication units involving $\mathrm{Si}$, $\mathrm{Mn}, \mathrm{Cu}, \mathrm{Ni}, \mathrm{Cr}, \mathrm{Mo}, \mathrm{V}, \mathrm{Nb}(\mathrm{Cb})$, and $\mathrm{B}$.
$\mathrm{A}(\mathrm{C})=0.75+0.25 \tanh [20 \times(\mathrm{C}-0.12)]$ and $\mathrm{EMU}=\{\mathrm{Si} / 24$ $+\mathrm{Mn} / 6+\mathrm{Cu} / 15+\mathrm{Ni} / 20+(\mathrm{Cr}+\mathrm{Mo}+\mathrm{V}+\mathrm{Nb}) / 5+5 \times \mathrm{B}\}$

$\mathrm{A}_{\mathrm{r} 3}\left({ }^{\circ} \mathrm{C}\right)=910-(310 \times \mathrm{C})-(80 \times \mathrm{Mn})-(80 \times \mathrm{Mo})-(55$ $\times \mathrm{Ni})-(20 \times \mathrm{Cu})-(15 \times \mathrm{Cr})$

$\mathrm{B}_{\mathrm{s}}\left({ }^{\circ} \mathrm{C}\right)=830-(270 \times \mathrm{C})-(90 \times \mathrm{Mn})-(37 \times \mathrm{Ni})-(70 \times \mathrm{Cr})$ $-(83 \times \mathrm{Mo})$

$\mathrm{B}_{50}\left({ }^{\circ} \mathrm{C}\right)=\mathrm{B}_{\mathrm{s}}\left({ }^{\circ} \mathrm{C}\right)-60=770-(270 \times \mathrm{C})-(90 \times \mathrm{Mn})-(37$ $\times \mathrm{Ni})-(70 \times \mathrm{Cr})-(83 \times \mathrm{Mo})$

$\mathrm{B}_{\mathrm{f}}\left({ }^{\circ} \mathrm{C}\right)=\mathrm{B}_{\mathrm{s}}\left({ }^{\circ} \mathrm{C}\right)-120=710-(270 \times \mathrm{C})-(90 \times \mathrm{Mn})-(37$ $\times \mathrm{Ni})-(70 \times \mathrm{Cr})-(83 \times \mathrm{Mo})$

$\mathrm{M}_{\mathrm{s}}\left({ }^{\circ} \mathrm{C}\right)=561-(474 \times \mathrm{C})-(33 \times \mathrm{Mn})-(17 \times \mathrm{Ni})-(17 \times \mathrm{Cr})$ $-(21 \times \mathrm{Mo})$

The above constitutive equations on solid-state phase transformation temperatures were developed several decades ago. The constitutive relationships are based on a variety of regularly manufactured steel samples. The experimental conditions ensured complete homogenization of the chemical composition, and full dissolution of second-phase particles, as $\mathrm{Nb}$, Ti, and V micro-alloy additions, besides $\mathrm{Mo}, \mathrm{W}, \mathrm{Cr}$, and $\mathrm{Mn}$, in decreasing order, showed the highest affinity to form carbides. These constitutive equations relate austenite transformation temperatures to the contents of principal alloy elements like C, Mn, Ni, Cr, Mo, and Cu but do not include the effects of various minor alloy elements like $\mathrm{Al}, \mathrm{O}, \mathrm{N}$, and particularly $\mathrm{Ti}$ and B. Consequently, one shouldn't expect that the calculated transformation temperatures would fully agree with experimental results of solid-state phase transformation temperatures, more so as they relate to WMs. 
The above calculations were performed using Microsoft Excel. Subsequently, the results were transposed (i.e., organized) to perform a variety of comparative analyses. The $\mathrm{Mi}$ crosoft Excel Workbook, Analysis of G. M. Evans SMAW Database, available on the AWS website (aws.org/2021.100. 036-database) contains a total of 11 spreadsheets. As mentioned earlier, Spreadsheet \#1 contains Evans's original database together with various calculated metallurgical characteristics, and Spreadsheet \#2 shows the four bestin-class WM compositions among the Fe-C-Mn WM compositions in the SMAW database. These four best-in-class WM compositions were identified by Evans following additional extensive testing of CVN impact properties over a full range of test temperatures.

Spreadsheets \#3 through \#11 allow comparative ranking based on a specific factor (or metallurgical characteristics) of interest. The reader may recognize that the CBM also allows comparative ranking of this database based on any other calculated metallurgical characteristics of interest.

Spreadsheet \#3 organizes the results with increasing CVN impact test temperatures for $28 \mathrm{~J}$ energy. Spreadsheet \#4 provides the results with increasing test temperatures for $28 \mathrm{~J}$ WM toughness with $-100^{\circ} \mathrm{C}$ as the cutoff. Spreadsheet \#5 offers the results with increasing test temperatures for $100 \mathrm{~J}$ WM toughness with $-60^{\circ} \mathrm{C}$ as the cutoff.

Spreadsheet \#6 presents the results with increasing carbon content. Spreadsheets \#7 through \#11 arrange results for decreasing Ni content, decreasing CEN, decreasing WM yield strength, decreasing $\mathrm{A}_{\mathrm{r} 3}$ transformation temperatures, and the increasing difference between $B_{f}$ and $M_{s}$ temperatures, respectively.

Except for the two regression equations related to $\mathrm{P}_{\mathrm{cm}}$ and Yurioka's $C E N$ that include $B$, the other regression equations related to the transformation temperatures do not include minor alloy elements like $\mathrm{Ti}, \mathrm{Al}, \mathrm{N}$, and $\mathrm{O}$. Therefore, application of the CBM to WM compositions doesn't allow one to study or analyze the interactive effects among minor alloy elements like $\mathrm{Ti}, \mathrm{Al}, \mathrm{N}, \mathrm{O}$, and $\mathrm{B}$ in various $\mathrm{Fe}-\mathrm{C}-\mathrm{Mn}$ alloy systems.

\section{Results and Discussion}

As shown in Spreadsheet \#1, rows \#366 (CB), \#783 (TiBN), and \#884 (TiB) showed identical WM chemical composition, calculated metallurgical characteristics, tensile strength (at $616 \mathrm{MPa}$ or $89 \mathrm{ksi}$ ), and CVN impact toughness values. A second set of rows, \#373 (CB), \#790 (TiBN), and \#891 (TiB), showed identical WM chemical composition, calculated metallurgical characteristics, tensile strength (at $617 \mathrm{MPa}$ or $89 \mathrm{ksi}$ ), and CVN impact toughness values. Similarly, a third set of rows, \#375 (CB), \#792 (TiBN), and \#893 (TiB), showed identical WM chemical composition, calculated metallurgical characteristics, tensile strength (at $610 \mathrm{MPa}$ or $88 \mathrm{ksi}$ ), and CVN impact toughness values. Although the above sets of rows supposedly represented three different sets of alloy systems, their reported WM chemical compositions were identical within each of these sets of rows. Therefore, their calculated metallurgical characteristics also showed identical values within each set of rows. Interestingly, all these three sets of rows of WMs showed a tight range for $\mathrm{C}$ and $\mathrm{Mn}$ contents but no other significant difference in WM chemical composition, values of
CEN, and various calculated transformation temperatures. These nine WMs offered high WM tensile strength and exceptional CVN impact properties.

The four best-in-class WMs shown in Spreadsheet \#2 correspond to rows \#139 (AlO), \#369 (CB), \#741 (TiBAlN), and \#936 (TiOX) in Spreadsheet \#1. These four best-in-class WMs revealed only nominal differences in WM composition (Table 3). For example, WM \#936 (TiOX) showed the lowest levels for $\mathrm{Ti}, \mathrm{O}, \mathrm{Al}$, and $\mathrm{B}$. However, there was no substantial difference in WM tensile and impact properties (Table 4) that didn't allow an easy comparison. In fact, the chemical composition of the above 13 rows of WMs (i.e., \#139 [AlO], \#366 [CB], \#369 [CB], \#373 [CB], \#375 [CB], \#741 [TiBAlN], \#783 [TiBN], \#790 [TiBN], \#792 [TiBN], \#884 [TiB], \#891 [TiB], \#893 [TiB], and \#936 [TiOX]) reminds one of modern TMCP steels such as HSLA-65 steels (Ref. 10). The HSLA-65 steels belong to ASTM A945, Standard Specification for HighStrength Low-Alloy Structural Steel Plate with Low Carbon and Restricted Sulfur for Improved Weldability, Formability, and Toughness, materials specification (Table 6) and contain controlled amounts of micro-alloy (i.e., $\mathrm{Nb}, \mathrm{Ti}$, and $\mathrm{V}$ ) additions for achieving refined grains following TMCP. As is well known, refining the grains increases strength while simultaneously increasing impact toughness. Yet, as one might expect, the SMAW WM test samples subjected to CVN impact testing may have contained areas under the notch that were reheated by weave, pass sequence, etc. depending on the actual weld procedure. These areas, as shown in Fig. 1, might have undergone sub-critical or critical temperature excursions or none at all, and the reheating might have also occurred multiple times. The resulting microstructure might contain adverse microstructural constituents that would aid crack propagation during impact testing, thereby reducing fracture resistance.

Fortunately, application of the CBM to these four bestin-class WMs allowed a ready comparison using their calculated metallurgical characteristics as shown in Table 7. Despite only nominal differences in the chemical composition of these four best-in-class WMs, it is interesting to note that the calculated metallurgical characteristics of the WMs (Table 7) didn't show significant differences, except for TiBAlN (row \#741, Spreadsheet \#1), which showed a lower $\mathrm{B}_{50}$ temperature at $607^{\circ} \mathrm{C}$. The lower $\mathrm{B}_{50}$ temperature appears consistent with a higher yield strength at $610 \mathrm{~N} / \mathrm{mm}^{2}$ (or $\mathrm{MPa}$ ) and tensile strength at $640 \mathrm{~N} / \mathrm{mm}^{2}$. Here, one might recognize that row \#936 (TiOX) WM showed relatively lower values for the various calculated transformation temperatures than row \#741 (TiBAlN) WM but also lower tensile properties. This seemingly anomalous behavior leads to a specific insight. In addition to a lower $B_{50}$ temperature, it is likely that the enhanced tensile properties and a higher upper shelf energy in CVN impact testing of row \#741 (TiBAlN) WM resulted from the combined effects of relatively higher levels of $\mathrm{Ti}, \mathrm{B}, \mathrm{Al}$, and $\mathrm{N}$ (than row \#936 [TiOX] WM) in forming complex inclusions that promoted the development of a fracture-resistant refined microstructure (Ref. 12). Row \#741 in Spreadsheet \#1 (TiBAlN) likely offered a baseline for $\mathrm{Ti}, \mathrm{B}, \mathrm{Al}$, and $\mathrm{N}$ contents to (1) achieve effective deoxidation, (2) form and uniformly distribute complex inclusions, and (3) develop fracture-resistant refined microstructural products in the WM. 
The choice or selection of consumable electrodes for fusion welding of high-strength steels used in the fabrication of structures and pressure vessels can immensely benefit from an understanding of the actual chemical composition, thermo-mechanical processing history, microstructure development, and mechanical properties of steels. For example, per ASTM A945 materials specification, HSLA-65 plate steels can be produced using one of five plate manufacturing techniques (Ref. 10): normalizing, controlled rolling, controlled rolling followed by accelerated cooling, direct Q\&T, or conventional Q\&T. As shown in Table 6, the commercially available HSLA-65 steels are characterized by a low-carbon content (below $0.10 \mathrm{wt}-\%$ ) and a low-alloy content, and they exhibit a low CEN (below 0.300) that allows improved plate weldability (Ref. 10). The above characteristics in turn (a) provide the steel plate with a refined ferritic or bainitic microstructure that ensures high strength and toughness; (b) eliminate or substantially reduce the need for preheating during welding; (c) resist susceptibility to hydrogen-assisted cracking in the weld heat-affected zone (HAZ) when fusion (arc) welded using low-heat-input conditions; and (d) depending on section thickness, facilitate high-heat-input welding (about $2 \mathrm{~kJ} / \mathrm{mm}$ or $51 \mathrm{~kJ} /$ in.) without significant loss of strength or toughness in the HAZ.

A comparison of Tables 3 and 6 shows a convergence in chemical composition, with particular emphasis on $\mathrm{Ti}$ and $\mathrm{Al}$ additions as shown in row \# 741, Spreadsheet \#1 (TiBAlN). Furthermore, as shown in Table 4, while AlO, CB, and TiOX systems offered barely above $552 \mathrm{MPa}$ (80 ksi) tensile strength, TiBAlN offered a much higher tensile strength at $640 \mathrm{MPa}$ (or over $92 \mathrm{ksi}$ ), indicating an ability to overmatch the tensile strength of HSLA-65 steel. In other words, it might be possible for the TiBAlN alloy system to accommodate HSLA-65 steel tensile requirements when using a wider welding operational envelope. In this respect, the calculated metallurgical characteristics of the four best-in-class WMs are consistent with prior recommendations made for highperformance GMAW electrodes for HSLA-65 steels, namely a calculated $A_{r 3}$ of $690^{\circ} \mathrm{C}$, a CEN of 0.29 , and a $\left(B_{f}-M_{s}\right)$ of $30^{\circ} \mathrm{C}$ (Ref. 6). Minor manipulation of the values for these metallurgical characteristics may be required particularly when one considers the row \#741, Spreadsheet \#1 (TiBAlN) WM composition against additional need for overmatching tensile strength and/or enabling the use of a wider welding operational envelope involving higher heat input.

The four best-in-class WMs in Spreadsheet \#1 (involving rows \#139 [AlO], \#369 [CB], \#741 [TiBAlN], and \#936 [TiOX]) as well as the three sets of duplicate WMs in Spreadsheet \#1 (involving rows \#366 [CB], \#373 [CB], \#375 [CB], \#783 [TiBN], \#790 [TiBN], \#792 [TiBN], \#884 [TiB], \#891 [TiB], and \#893 [TiB]) offered a baseline of chemical compositions for a WM high-tensile strength of more than 558 $\mathrm{MPa}$ (about $81 \mathrm{ksi}$ ) and exceptional CVN impact toughness. Their $C$ content ranged between 0.070 and 0.085 wt- $\%$, Mn content ranged between 1.35 and 1.63 wt-\%, Ti content ranged between 0.0025 and $0.061 \mathrm{wt}-\%$, and $\mathrm{B}$ content ranged between 0.0002 and 0.0059 wt-\% while the CEN value ranged between 0.235 and 0.263 . Here, the Ti content ranging between 0.0025 and $0.0061 \mathrm{wt}-\%$ was able to tolerate a wider range of combined nitrogen and oxygen contents, ranging from 0.0281 to 0.0505 wt-\%. The calculated transformation temperatures fell in a tight range, with a calculated $\mathrm{A}_{\mathrm{r} 3}$ between $750^{\circ}$ and $773^{\circ} \mathrm{C}$ as well as $\mathrm{B}_{\mathrm{s}}$ between $657^{\circ}$ and $682^{\circ} \mathrm{C}$. Their calculated $\left(\mathrm{B}_{\mathrm{f}}-\mathrm{M}_{\mathrm{s}}\right)$ difference ranged between $71^{\circ}$ and $86^{\circ} \mathrm{C}$.

Spreadsheet \#3 rearranges the database with increasing CVN test temperatures for $28 \mathrm{~J}$ energy. The alloy systems with 5 and 3 wt-\% Ni showed exceptional lowering of CVN test temperatures for $28 \mathrm{~J}$ energy. Invariably, the CrMo alloy systems showed very high (but unacceptable) CVN test temperatures for $28 \mathrm{~J}$ energy. In most alloy systems, when the $\mathrm{Cr}$ level increased above $0.05 \mathrm{wt}-\%$, the $\mathrm{C}$ content had to remain low with the possible addition of Ti to restore low CVN test temperatures for $28 \mathrm{~J}$ energy. Similarly, the addition of Mo above 0.5 wt-\% seemed to result in excessive reduction or ultimately a reversal in the calculated $\left(B_{f}-M_{s}\right)$ temperature. Near elimination of $\mathrm{Cr}$ and control of both $\mathrm{Ni}$ and $\mathrm{Mo}$ (about $0.5 \mathrm{wt}-\%$ ) appeared critical to achieving a common progression of transformation temperatures, wherein $\mathrm{A}_{\mathrm{r} 3}>\mathrm{B}_{\mathrm{s}}>\mathrm{B}_{\mathrm{f}}>\mathrm{M}_{\mathrm{s}}$, and desirable transformation temperature ranges for producing high-strength steel WM with high toughness.

When considering impact toughness, a neural network analysis (Ref. 3) has shown that one should consider test temperatures for both 28 and $100 \mathrm{~J}$ impact toughness values. Spreadsheet \#4 offers the database with increasing CVN impact test temperatures for $28 \mathrm{~J} \mathrm{WM}$ toughness with $-100^{\circ} \mathrm{C}$ as a cutoff. Here, only 61 WM chemical compositions showed 28 $\mathrm{J}$ impact energy at $-100^{\circ} \mathrm{C}$ or colder. Their WM tensile strength ranged between $537 \mathrm{MPa}(77.8 \mathrm{ksi})$ and $708 \mathrm{MPa}$ (102.6 ksi). In fact, the AlO alloy system (row \#139 in Spreadsheet \#1) that belonged to the four best-in-class WMs dropped out of this listing. The $C$ content of these 61 alloy systems varied between a low of $0.038 \mathrm{wt}-\%$ and a high of $0.085 \mathrm{wt}-\%$, while the CEN ranged between 0.191 and 0.292 . It is instructive to recognize that at about $0.12 \mathrm{wt}-\% \mathrm{C}$, the morphology of martensite changes from needles to plates, and this morphological change in WM microstructure has an adverse effect on both fracture toughness and hydrogen-induced cracking sensitivity. Controlling the $C$ content below 0.10 wt- $\%$ seems desirable. These 61 WM chemical compositions also showed a narrowing of the range for actual WM chemical compositions as well as various calculated metallurgical characteristics, thereby offering a target range for calculated metallurgical characteristics for successful electrode development to meet up to 705 $\mathrm{MPa}$ (102 ksi) WM tensile strength. Interestingly, rows \#57 (CB), \#61 (TiBN), and \#63 (TiB) alloy systems in Spreadsheet \#4, all revealing the same WM compositions, calculated WM characteristics, and WM tensile and CVN impact properties, showed a Ti content as high as 0.061 wt-\% that provided the WMs with a very high CVN impact toughness.

Spreadsheet \#5 organizes the database with increasing CVN impact test temperatures for $100 \mathrm{~J}$ WM toughness with $60^{\circ} \mathrm{C}$ as a cutoff. This listing showed a total of 256 electrode WM chemical compositions, with all four best-in-class WMs appearing in this listing. The $C$ content of these $256 \mathrm{WM}$ chemical compositions varied between a low of $0.038 \mathrm{wt}-\%$ to a high of 0.103 wt-\%, while the CEN ranged between 0.138 and 0.292 . Here, again, controlling the $C$ content below 0.10 wt-\% seemed desirable. Compared to the 61 WM chemical compositions listed in Spreadsheet \#4, these 256 WM chemical compositions showed a broadening of the range for the var- 
ious calculated metallurgical characteristics. The WM tensile strength of these 256 WMs ranged between $452 \mathrm{MPa}(65.5$ $\mathrm{ksi}$ ) and $708 \mathrm{MPa}$ (102.6 ksi). While the $61 \mathrm{WM}$ compositions in Spreadsheet \#4 showed a CEN value ranging between 0.191 and 0.292, the 256 WMs listed in Spreadsheet \#5 showed a broadening of the CEN range between 0.138 and 0.292 , thus causing a lowering of the range for WM tensile strength. Spreadsheet \#5 also showed six alloy systems (involving rows \#63 [CB], \#64 [TiBN], \#65 [TiB], \#146 [CB], \#151 [TiBN], and $\# 154$ [TiB]) with the Ti content at $0.061 \mathrm{wt}-\%$ and a very high CVN impact toughness. A closer examination revealed these six alloy systems belonged to two sets of identical WM compositions, and one of these two is the same as rows \#57 (CB), \#61 (TiBN), and \#63 (TiB) alloy systems listed in Spreadsheet \#4.

Spreadsheet \#6 arranges the database with increasing $C$ content. As the $C$ content increased, the strength increased. At a given $C$ content, as the $C E N$ increased, the strength continued to increase. Data reported in rows \#306 and \#307 referring to the CrMo alloy system is particularly instructive. Here, at a constant $C$ content of 0.068 wt- $\%$, increasing the Mo content from 0.005 to 1.13 wt-\% allowed the CEN to jump from 0.180 to 0.701 and indiscriminately lowered the $M_{s}$ temperature, causing the difference between $B_{f}$ and $M_{s}$ temperatures to decrease from $100^{\circ}$ to $-141^{\circ} \mathrm{C}$. This reversal indicates a partial violation of the common progression of transformation temperatures, wherein $A_{r 3}>B_{s}>B_{f}>M_{s}$, with $\mathrm{M}_{\mathrm{s}}>\mathrm{B}_{\mathrm{f}}$. Consequently, the yield strength increased from 424 to $1018 \mathrm{MPa}$ with a corresponding adverse effect on CVN impact toughness values. Similar trends were noticeable in other alloy systems, for example, the CoPlus system detailed in rows \#714 to \#717.

Spreadsheet \#7 organizes the database with decreasing $\mathrm{Ni}$ content. In general, increasing the Ni content offered to simultaneously increase both strength and CVN impact toughness. However, at nearly 5 wt-\% Ni addition, the calculated $A_{\mathrm{r} 3}$ temperature was lower than the calculated $B_{s}$ temperature. This violated the common progression of transformation temperatures, wherein $A_{r 3}>B_{s}>B_{f}>M_{s}$, with $A_{r 3}$ $<\mathrm{B}_{s}$. Yet, this didn't cause an adverse consequence on CVN impact toughness, except for minor variations. Data reported in row \#17, Spreadsheet \#7 for A5Ni seemed rather anomalous or an aberration from other WMs based on the $\mathrm{A} 5 \mathrm{Ni}$ system. It is likely that a combination of low $\mathrm{Ti}$ and $\mathrm{Al}$ contents might have contributed to the anomalous behavior. Additionally, as both $\mathrm{Ni}$ and $\mathrm{C}$ tend to stabilize austenite, a combination of higher $\mathrm{Ni}$ and $\mathrm{C}$ contents in rows \#3 through \#27 lowered the calculated $\mathrm{A}_{\mathrm{r} 3}$ temperature below the calculated $B_{s}$ temperature. As shown in Spreadsheet \#1 (involving rows \#366 [CB], \#373 [CB], \#375 [CB], \#783 [TiBN], \#790 [TiBN], \#792 [TiBN], \#884 [TiB], \#891 [TiB], and \#893 $[\mathrm{TiB}])$ as well as the four best-in-class involving rows \#139 [AlO], \#369 [CB], \#741 [TiBAlN], and \#936 [TiOX]), one needs to manipulate the chemical composition of the electrode and WM so the calculated $\mathrm{A}_{\mathrm{r} 3}$ temperature stays above the calculated $\mathrm{B}_{\mathrm{s}}$ temperature to obtain consistently high WM CVN impact toughness values. The benefit of this approach is seen in WMs associated with the A3Ni alloy system wherein the calculated difference $\left(A_{r 3}-B_{s}\right)$ was in excess of $30^{\circ} \mathrm{C}$.

Spreadsheet \#8 presents the results with a decreasing CEN. As the calculated value of the CEN decreased from 0.780 to
0.401 (rows \#3 through \#27), the WM tensile strength decreased from 1055 to $710 \mathrm{MPa}$. A calculated CEN value of 0.400 appeared necessary to achieve a WM tensile strength in excess of $700 \mathrm{MPa}$ (over $100 \mathrm{ksi}$ ). Invariably, almost all of these WM compositions (except for the CMn alloy system with 0.141 wt-\% C content, row \# 394 in Spreadsheet \#1) didn't provide acceptable CVN impact toughness. This likely represents the preferential formation of athermal transformation products in the WM. Here, the unacceptable CVN impact values correlated with very large negative values for $\left(B_{f}-M_{s}\right)$. In comparison, the ER100S and ER120S electrodes that were metallurgically designed using the CBM and successfully met the U.S. Navy requirements for both WM strength and CVN impact toughness showed a higher value for $\mathrm{B}_{50}$ and a relatively lower value for $M_{s}$, thereby providing a positive difference in the calculated $\left(B_{50}-M_{s}\right)$ value (Ref. 4$)$.

Spreadsheet \#9 provides the database with decreasing WM tensile strength. One could also organize Spreadsheet \#9 based on yield strength (which is rarely used as a design parameter) and/or yield-to-tensile ratio. The yield-to-tensile ratio of the WMs in the SMAW database ranged between 0.79 (Spreadsheet \#9, row \#935, AB alloy system) and 0.97 (row \#241, TiBAlN alloy system). Commonly, when the yield-to-tensile ratio of the high-strength steel WM is about 0.80 , one could expect improved toughness, and as the yield-to-tensile ratio increases further, one could expect a substantial reduction in fracture toughness, especially at lower test temperatures. However, row \#241, TiBAlN alloy system, seemed an exception as it also provided one of the best CVN impact toughness values. This could be attributed to possible formation of extremely refined grains. It is well known that the presence of refined grains in WM simultaneously improves both strength and toughness. Among the various alloy systems shown, the tensile strength decreased from a high of $1123 \mathrm{MPa}$ to a low of 345 $\mathrm{MPa}$. Rows \#3 through \#15 of Spreadsheet \#9 showed the highest tensile strength, and they all belonged to the $\mathrm{CrMo}$ alloy system. Here again, the CrMo alloy systems invariably showed a very high tensile strength and high yield-to-tensile ratios between 0.81 and 0.94 but a very high or unacceptable CVN impact test temperature for $28 \mathrm{~J}$ energy. Most CrMo alloys didn't meet the CVN impact test temperature requirement for $100 \mathrm{~J}$ energy. Based on an analysis of the results reported in Spreadsheets \#3, \#4, and \#5, one could reach a conclusion that in general the CrMo system didn't offer adequate promise as a candidate alloy system for high-strength, highperformance steel electrode development. As the strength of the WM increases over $700 \mathrm{MPa}(101.5 \mathrm{ksi})$, the yield-to-tensile ratio often exceeds 0.90 , which is known to cause reduced fracture toughness. As a notable exception, row \#38, A5Ni alloy system, showed that when $\mathrm{Ni}$ is an alloy addition to stabilize austenite or lower the calculated $A_{r 3}$ temperature to $563^{\circ} \mathrm{C}$ and nearly match the calculated $\mathrm{B}_{\mathrm{s}}$ temperature, high or acceptable WM toughness could be achieved at $708 \mathrm{MPa}$ (102 ksi) WM tensile strength. Here, the yield-to-tensile ratio showed a value of 0.91 .

Spreadsheet \#10 shows the results with decreasing $\mathrm{A}_{\mathrm{r} 3}$ temperatures. Interestingly, a combination of a decreasing $\mathrm{A}_{\mathrm{r} 3}$ temperature and decreasing CEN seemed to provide exceptional toughness albeit at a lower WM strength. In general, the combination of a calculated $\mathrm{A}_{\mathrm{r} 3}$ temperature below $750^{\circ} \mathrm{C}$ and a calculated CEN below 0.300 appeared desirable in engineering 
the chemical composition of Fe-C-Mn alloy systems to provide high-performance steel electrodes with more than $552 \mathrm{MPa}$ (80 ksi) WM tensile strength, which is suitable for the fabrication of HSLA-65 steels.

Spreadsheet \#11 provides the database with increasing differences between the calculated $\mathrm{B}_{\mathrm{f}}$ and $\mathrm{M}_{\mathrm{s}}$ temperatures. The difference between the calculated $\mathrm{B}_{\mathrm{f}}$ and $\mathrm{M}_{\mathrm{s}}$ temperatures appeared critical to achieving exceptional CVN impact toughness. In fact, the first nine listings of Spreadsheet \#10 refer to $\mathrm{CrMo}$ systems. An analysis of the relationships among the calculated solid-state phase transformation temperatures showed that the $\left(B_{f}-M_{s}\right)$ had to remain positive. In other words, the calculated $\mathrm{M}_{\mathrm{s}}$ temperature must be lower than the calculated $\mathrm{B}_{\mathrm{f}}$ temperature, meaning one should manipulate the WM chemical composition to preclude the preferential transformation of austenite to martensite as much as possible. A nominal value of $\left(B_{f}-M_{s}\right)=70 \pm 10^{\circ} \mathrm{C}$ seemed to offer exceptional toughness results, although one could notice a few exceptions or outliers. Most likely, these outliers represent preferential formation of athermal transformation products containing a lower $C$ content at less than $0.10 \mathrm{wt}-\%$.

Coincidentally, a combination of $C$ content less than 0.08 wt-\%, a CEN less than 0.400 (or corresponding to about 700 $\mathrm{MPa}$ or $101 \mathrm{ksi}$ WM tensile strength), and a $\left(\mathrm{B}_{\mathrm{f}}-\mathrm{M}_{\mathrm{s}}\right)=70$ $\pm 10^{\circ} \mathrm{C}$ appeared to augur well for improving CVN impact toughness or lowering the ductile-to-brittle CVN impact transition temperature. This finding is also consistent with previously published recommendations on how to select welding electrodes for joining high-strength steels (Ref. 13).

While the application of a CBM to WM compositions doesn't allow one to study and analyze the interactive effects of minor alloy elements like Ti, $\mathrm{Al}, \mathrm{N}, \mathrm{O}$, and $\mathrm{B}$ in various $\mathrm{Fe}-\mathrm{C}-$ Mn alloy systems without additional supporting microstructural analysis of the WM (Ref. 12), it appeared that TiBAlN (Spreadsheet\#1, row \#741) likely provided a target for electrode aim compositions with Ti at $0.042 \mathrm{wt}-\%, \mathrm{~B}$ at $0.0048 \mathrm{wt}-$ $\%, \mathrm{Al}$ at $0.016 \mathrm{wt}-\%$, and $\mathrm{N}$ at $0.0067 \mathrm{wt}-\%$ to (1) achieve effective deoxidation, (2) form complex inclusions, and (3) distribute them to enable development of a fracture-resistant refined WM microstructure.

Titanium addition has been found to provide a unique effect on the microstructure and properties of ferritic steel WMs when a balance is achieved with other elements present, leading to two optima (Ref. 14). The CVN impact toughness of SMA WMs containing either of the two optima, namely 30 ppm and 180 to 400 ppm Ti content, remained robust across a range of weld cooling rates (Ref. 15). This behavior was attributed to the formation of a predominantly acicular ferrite microstructure. Titanium is known to form a variety of oxides such as $\mathrm{TiO}, \mathrm{Ti}_{2} \mathrm{O}_{3}, \mathrm{Ti}_{3} \mathrm{O}_{5}$, and $\mathrm{TiO}_{2}$. Of these oxides, $\mathrm{TiO}$ has the lowest Gibbs free energy $(\Delta G)$, therefore TiO is most likely to form a stable oxide. The TiO inclusions appear to serve as effective sites for intragranular nucleation of acicular ferrite. While nitrogen addition is generally deleterious to WM CVN impact toughness, it could be beneficial when boron addition is at about $40 \mathrm{ppm}$ (Ref. 16). Dilatometric evaluation of transformation kinetics of Ti-B-N-type WMs showed that the addition of $40 \mathrm{ppm} B$ retarded the transformation start temperature associated with the formation of grain boundary ferrite from $760^{\circ}$ to $705^{\circ} \mathrm{C}$, thus enabling the formation of a predominantly acicular ferrite WM microstructure.
The above experimental observation of reheated WM attests to the fact that one could reduce relevant transformation temperatures using a dual approach wherein the contents of principal alloy elements such as $\mathrm{C}, \mathrm{Mn}, \mathrm{Ni}, \mathrm{Cr}, \mathrm{Mo}$, and $\mathrm{Cu}$ are manipulated while controlled amounts of $\mathrm{Ti}, \mathrm{B}, \mathrm{Al}, \mathrm{O}$, and $\mathrm{N}$ are added, thereby ensuring high-strength and high-toughness WMs. Together, Tables 3 and 7 illustrate the benefits of this dual approach. As controlled additions of $\mathrm{Ti}, \mathrm{B}, \mathrm{Al}, \mathrm{O}$, and $\mathrm{N}$ present in row \#741, TiBAlN WM, provide superior tensile and CVN impact properties over row \#936, TiOX WMs, despite the latter showing relatively lower values for the various calculated transformation temperatures.

\section{Conclusion}

1) The CBM offers a simple and effective means to organize a very large SMAW database involving a variety of $\mathrm{Fe}-\mathrm{C}-\mathrm{Mn}$ alloy systems, allows one to categorize the results under various calculated metallurgical characteristics of interest, and enables one to comparatively analyze the results in gaining valuable insights.

2) Analysis of Evans's large SMA WM database using the CBM affirmed that controlling the $C$ content, the $C E N$ value, and the calculated solid-state phase transformation temperatures, particularly the difference between the calculated $\mathrm{B}_{\mathrm{f}}$ and $M_{s}$ temperatures, is critical to developing and identifying highperformance, high-strength steel welding electrodes.

3) Analysis of the database using the CBM revealed the following valuable insights:

a) The exceptional CVN impact toughness of the four bestin-class Fe-C-Mn WMs (Spreadsheet \#2) provided a target for a $C$ content below $0.10 \mathrm{wt}-\%$ and a desirable set of calculated metallurgical characteristics with a CEN below 0.300 , an $\mathrm{A}_{\mathrm{r} 3}$ temperature value at about $750^{\circ} \mathrm{C}$, and a $\mathrm{B}_{50}$ temperature value at about $600^{\circ} \mathrm{C}$.

b) In particular, TiBAlN (Spreadsheet\#1, row \#741) likely provides a target for electrode aim compositions with the Ti at $0.042 \mathrm{wt}-\%, \mathrm{~B}$ at $0.0048 \mathrm{wt}-\%, \mathrm{Al}$ at $0.016 \mathrm{wt}-\%$, and $\mathrm{N}$ at $0.0067 \mathrm{wt}-\%$ to achieve effective deoxidation and to form complex inclusions and distribute them to enable development of a fracture-resistant refined WM microstructure.

c) In general, the CrMo system didn't offer adequate promise as a candidate alloy system for high-strength, highperformance steel electrode development as most CrMo alloy WM compositions didn't meet the CVN impact test temperature requirement for $100 \mathrm{~J}$ energy.

d) With the $C$ content below $0.10 \mathrm{wt}-\%$, a combination of a calculated $\mathrm{A}_{\mathrm{r} 3}$ temperature above $750^{\circ} \mathrm{C}$, calculated $\mathrm{B}_{50}$ temperature at about $600^{\circ} \mathrm{C}$, and calculated CEN below 0.300 appeared desirable in engineering the chemical composition of Fe-C-Mn alloy systems to provide high-performance steel electrodes with more than $552 \mathrm{MPa}(80 \mathrm{ksi})$ WM tensile strength suitable for the fabrication of HSLA-65 steels.

e) The calculated value of the $A_{r 3}$ temperature needs to be $60^{\circ}$ to $100^{\circ} \mathrm{C}$ above the calculated value of the $B_{s}$ temperature to obtain consistently high WM CVN impact toughness values. This likely represents the formation of predominantly diffusional transformation products in the WM.

f) A calculated $B_{50}$ temperature value below $600^{\circ} \mathrm{C}$ appeared necessary to achieve WM tensile strength in excess of 552 
$\mathrm{MPa}(80 \mathrm{ksi})$. Here, a nominal value of $\left(\mathrm{B}_{\mathrm{f}}-\mathrm{M}_{\mathrm{s}}\right)=70 \pm 10^{\circ} \mathrm{C}$ seemed to offer exceptional toughness results.

g) Addition of Mo in excess of $0.50 \mathrm{wt}-\%$ caused indiscriminate lowering of the calculated value of the $M_{s}$ temperature and allowed the difference between $B_{f}$ and $M_{s}$ temperatures to reverse from positive to negative. With this result, the yield strength increased at the expense of unacceptable WM CVN impact toughness values. It is preferable to manipulate the contents of principal alloy elements to retain the common progression of transformation temperatures, wherein $\mathrm{A}_{\mathrm{r} 3}>\mathrm{B}_{\mathrm{s}}>\mathrm{B}_{\mathrm{f}}>\mathrm{M}_{\mathrm{s}}$.

h) A calculated CEN value of 0.400 appeared necessary to achieve WM tensile strength in excess of $700 \mathrm{MPa}$ (over 100 $\mathrm{ksi}$ ). This likely represents preferential formation of athermal transformation products in the WM.

4) Without the help of the CBM, it might be virtually impossible to analyze the large SMAW database containing more than $950 \mathrm{WM}$ chemical composition and mechanical property data to develop the above set of valuable insights.

\section{Acknowledgments}

The author remains grateful to Dr. Glyn M. Evans for his encouragement, technical guidance, and support. The author is also thankful to the AWS peer reviewers for their helpful comments on the manuscript.

\section{References}

1. Evans, G. M. 2015. Database - Weld metal composition and Properties. researchgate.net/publication/275963276_Database_Weld_metal_composition_and_properties. DOI: 10.13140/ RG.2.1.3628.1764

2. Evans, G. M., and Bailey, N. 1999. Metallurgy of Basic Weld Metal. Abington, UK: Abington Publishing.

3. Evans, G. M. 2018. IIW Doc.II-C-546-18, A reassessment of the predictive Charpy-V toughness of the manganese-nickel weld metal combination. IIW Intermediate Meeting Sub-Comm.IIC, Genova, Italy.

4. Sampath, K. 2005. Constraints-based modeling enables successful development of a welding electrode specification for critical navy applications. Welding Journal 84(8): 131-s to 138-s.
5. Sampath, K., and Varadan, R. 2006. Evaluation of chemical composition limits of GMA welding electrode specifications for HSLA-100 steel. Welding Journal 85(8): 163-s to 173-s.

6. Sampath, V., Kehl Jr., J., Vizza, C., Varadan, R., and Sampath, K. 2008. Metallurgical design of high-performance GMAW electrodes for joining HSLA-65 steel. Journal of Materials Engineering and Performance 17(6): 808-830. DOI: 10.1007/s11665-008-9236-2

7. Sampath, K., and Green, R. S. 1996. U.S. Patent 5,744,782A, Advanced consumable electrodes for gas metal arc (GMA) welding of high strength low alloy (HSLA) steels.

8. Sampath, K., Green, R.S., Civis, D. A., Dong, H., and Konkol, P. J. 1995. Evaluation of new high performance electrodes for GMA welding of HSLA-100 steel. High Performance Structural Steels. Asfahani, R., Ed. Materials Park, Ohio: ASM International.

9. Coldren, P. A., Fiore, S. R., and Smith, R. B. 1996. U.S. Patent $5,523,540$, Welding electrodes for producing low carbon bainitic ferrite weld deposits.

10. Sampath, K. 2006. An understanding of HSLA-65 plate steels. Journal of Materials Engineering and Performance 15(1): 32-40. DOI: 10.1361/105994906x83439

11. Sharma, R., and Reisgen, U. 2018. Assessment of mechanical properties in high strength steel weld metals by means of phase transformation temperature. Welding in the World 62(6): 1227-1236. DOI: 10.1007/s40194-018-0605-7

12. Jorge, J. C. F., de Souza, L. F. G., Mendes, M. C., Bott, I. S., Araújo, L. S., dos Santos, V. R., Rebello, J. M. A., and Evans, G. M. 2021. Microstructure characterization and its relationship with impact toughness of C-Mn and high strength low alloy steel weld metals - A review. Journal of Materials Research and Technology 10: 471-501. DOI: 10.1016/j.jmrt.2020.12.006

13. Sampath, K. 2007. How to choose electrodes for joining high-strength steels. Welding Journal 86(7): 26-28.

14. Evans, G. M. 1996. Microstructure and properties of ferritic steel welds containing Ti and B. Welding Journal 75(8): 251-s to 260-s.

15. Johnson, M. Q., Evans, G. M., and Edwards, G. R. 1995. The influence of titanium additions and interpass temperature on the microstructures and mechanical properties of high strength SMA weld metals. ISIJ International 35(10): 1222-1231. DOI: 10.2355/ isijinternational.35.1222

16. Ilman, M. N., Cochrane, R. C., and Evans, G. M. 2012. Effect of nitrogen and boron on the development of acicular ferrite in reheated C-Mn-Ti steel weld metals. Welding in the World 56(11-12): 41-50. DOI: $10.1007 / \mathrm{bf03321394}$

K. SAMPATH (krishna.sampath@icloud.com) is with Creative Concepts, Marietta, Ga. 